\section{Drs. Codullo and Montecucco reply}

\section{To the Editor:}

We have read with much interest the letter of Nguyen, et al on the association of anti-RNA polymerase (RNAP) III antibodies with scleroderma renal crisis (SRC). The authors observed the aforementioned association in reviewing cases of SRC in a big US registry of patients with systemic sclerosis (SSc) and evaluating ethnic background and clinical and serologic profiles of their patients. Moreover, their study has confirmed a previous observation by ourselves ${ }^{1}$ of an earlier development of SRC during the disease course in anti-RNAP III-positive patients compared to the anti-topoisomerase I (anti-topo I) subset. This finding highlights similarities in the onset and the dynamics of this acute renal complication within serologic groups across patient populations, and further stresses the prognostic importance of determining autoantibody reactivities in SSc.

The discrepancies between our study ${ }^{1}$ and Dr. Nguyen's in the prevalence and clinical associations of autoantibody subsets are not unexpected. They are supported by evidence from data in the literature and can be explained by a number of considerations, including the different nature of the 2 analyses. First, our study did not aim to assess the association of SRC to the anti-RNAP III serologic subset given methodological limitations due to the rarity of the complication in Italian SSc patients ${ }^{2,3}$, the retrospective design of our survey, and the collection of patients from different centers. Hence, it cannot be excluded that a higher frequency of anti-RNAP III within SRC patients was missed in our study because of selection bias and the lack of a proper control group, as also noted by Nguyen, et al. Second, the distribution of serologic subsets, with more frequent anti-topo I reactivity in our SRC series, reflects differences observed in the whole SSc Italian population versus other SSc populations from other ethnic groups and geographic areas (Anglo-Saxons in particular) ${ }^{3,4}$, and is in accord with a recent study by Meyer, et al reporting significantly different autoantibody distributions in cohorts of patients from France and the US ${ }^{5}$. In Italy, both anti-RNAP III and renal involvement are relatively rare occurrences that make patient recruitment rather difficult, but we definitely agree with Nguyen, et al that a prospective study would clarify the association of the autoantibody status with renal crisis. Development of reliable routine laboratory tests to determine serologic profile ${ }^{6}$ has contributed to a better understanding of the distribution and clinical associations of autoantibody subsets in different geographic areas and makes possible the screening of large groups of patients, a critical step especially in the early diagnostic phases and in prognostic stratification ${ }^{7}$.

VERONICA CODULLO, MD; CARLOMAURIZIO MONTECUCCO, MD, Chair, Division of Rheumatology, University of Pavia, IRCCS Policlinico San Matteo Foundation, Pavia, Italy. Address correspondence to Dr. Montecucco. E-mail: montecucco@smatteo.pv.it

\section{REFERENCES}

1. Codullo V, Cavazzana I, Bonino C, Alpini C, Cavagna L, Cozzi F, et al. Serologic profile and mortality rates of scleroderma renal crisis in Italy. J Rheumatol 2009;36:1464-9.

2. Ferri C, Valentini G, Cozzi F, Sebastiani M, Nichelassi C, La Montagna G, et al. Systemic sclerosis: demographic, clinical and serologic features and survival in 1012 Italian patients. Medicine 2002;81:139-53.

3. Bardoni A, Rossi P, Salvini R, Bobbio-Pallavicini F, Caporali R, Montecucco C. Autoantibodies to RNA-polymerases in Italian patients with systemic sclerosis. Clin Exp Rheumatol 2003; 21:301-6.

4. Steen VD. Autoantibodies in systemic sclerosis. Semin Arthritis Rheum 2005;35:35-42.

5. Meyer O, Fertig N, Lucas M, Somogyi N, Medsger TA Jr. Disease subsets, antinuclear antibody profile, and clinical features in 127 French and 247 US adult patients with systemic sclerosis. J Rheumatol 2007;34:104-9.

6. Codullo V, Morozzi G, Bardoni A, Salvini R, Deleonardi G, De Pità $\mathrm{O}$, et al. Validation of a new immunoenzymatic method to detect antibodies to RNA polymerase III in systemic sclerosis. Clin Exp Rheumatol 2007;25:373-7.

7. Koenig M, Joyal F, Fritzler MJ, Roussin A, Abrahamowicz M, Boire $\mathrm{G}$, et al. Autoantibodies and microvascular damage are independent predictive factors for the progression of Raynaud's phenomenon to systemic sclerosis: a twenty-year prospective study of 586 patients, with validation of proposed criteria for early systemic sclerosis. Arthritis Rheum 2008;58:3902-12.

J Rheumatol 2010;37:5; doi:10.3899/jrheum.091264 